\title{
A comparative study of the clinical characteristics of breast cancer patients less than 35 years old and older patients
}

Tae Sik Hwang ${ }^{1}$, Ah Rem Jeong ${ }^{1}$, Joung Won Na', Yun Yeong Kim ${ }^{1,2}$, Joon-Hyop Lee ${ }^{1,2}$, Yoo Seung Chung ${ }^{1,2}$, Sang Tae Choi ${ }^{1,2}$, Jin Mo Kang ${ }^{1,2}$, Heung Kyu Park', ${ }^{1,2}$, Yong Soon Chun ${ }^{1,2}$

${ }^{1}$ Department of Surgery, Gil Medical Center, Incheon;

${ }^{2}$ Department of Surgery, Gachon University College of Medicine, Incheon, Korea

Purpose: In Korea, the incidence of breast cancer peaks in the fifth decade, which is younger than that observed in the Western world. We conducted this study to compare the clinical characteristics and prognostic factors of breast cancer in women $<35$ and $\geq 35$ years old.

Methods: The medical records of 969 patients treated for breast cancer at the Gil Medical Center from 2008 through 2012 were reviewed. Tumor characteristics, surgical methods, and adjuvant therapies were compared in two groups.

Results: Number of childbirths, family history, the proportion of postmenopausal women were lower among those aged $<35$ years. However, tumor size, number of metastatic lymph nodes, and surgical procedures were similar in two groups. The rate of triple negative status in younger patients was higher than in older patients. Adjuvant chemotherapy was effective in patients positive for hormone receptors and no lymph nodal invasion, and it was effective in patients negative for hormone receptors and lymph nodal invasion in patients aged $>35$ years old. Postoperative radiotherapy was statistically effective in patients aged $<35$ and $\geq 35$ years old that underwent breast-conserving surgery. Pregnancy were significantly associated with survival in younger patients. While lymph node stage, presence of progesterone receptor, and triple negative status were significantly associated with survival on older patients.

Conclusion: The prognostic factors of breast cancer in patients younger than 35 years old were pregnancy. Triple negative status rate was higher in younger patients than in older patients. Adjuvant therapy had similar effects in patients aged $<35$ or $\geq 35$ years old.

Keywords: Breast neoplasms, Prognosis, Young adult

\section{INTRODUCTION}

The incidence of breast cancer is rapidly increasing worldwide. In Korea, survival has increased due to progress in diagnostic and therapeutic techniques (83.2\% in 1996-2000, 88.5\% in 2001-2005, and $91.3 \%$ in 2008 ) Breast cancer is the second most common cancer next to thyroid cancer in Korean women [1,2].

The incidence of breast cancer varies according to age. As of 2014, median age at diagnosis was in the 50s but peak incidence

Received: Apr 3, 2018 Accepted: Jun 18, 2018

Correspondence to: Yong Soon Chun

Department of Surgery, Gachon University Gil Medical Center, 21 Namdong-daero 774beon-gil, Namdong-gu, Incheon 21565, Korea

Tel: +82-32-458-2731, Fax: +82-32-460-3247

E-mail: chunysmd@gachon.ac.kr

Copyright ( $($ Korean Society of Surgical Oncology

This is an Open Access article distributed under the terms of the Creative Commons Attribution Non-Commercial License (http://creativecommons.org/licenses/by-nc/4.0) which permits unrestricted non-commercial use, distribution, and reproduction in any medium, provided the original work is properly cited. was in the $40 s(40 s>50 s>60 s>30 s>70 s)[3]$

In Korea, the incidence of breast cancer among premenopausal and younger patients ( $<40$ years old) is twice that in Western countries. Furthermore, survival rates of young breast cancer patients are low and recurrences rate are high, and thus it is important the clinical features and prognostic factors of breast cancer in young patients be identified, and that appropriate treatment policies be developed to treat women in their 20s and 30s, which experience rapid physiological changes due to pregnancy, childbirth, and breastfeeding [4].

This study was undertaken to assess the clinical characteristics of breast cancer patients aged $<35$ years old and to compare these with those of patients $\geq 35$ years.

\section{METHODS}

Nine hundred and sixty-nine patients that underwent surgery due to invasive ductal carcinoma in the Gil Medical Center from Janu- 
ary 2008 to December 2012 were enrolled. The American Joint Committee on Cancer classification was used to classify breast cancer. Hospital medical and electronic records provided details of family history of breast cancer, presence of menopause, number of children born, tumor sizes, numbers of metastatic axillary lymph nodes, hormone receptor status, disease stage, and cause of death. Mean follow-up was 44.4 months.

Overall survival rate, survival rates for operative and adjunctive therapies, and prognostic factors were examined. Immunohistochemistry (IHC) was performed for the presence of hormone receptor. Human epidermal growth factor receptor 2 (HER2) overexpression was regarded as present in cases triple positive by IHC or positive by fluorescence in situ hybridization (FISH) or silver-enhanced in situ hybridization (SISH).

Statistical analysis was conducted using SPSS version 23.0 (IBM Corp., Armonk, NY, USA) for Windows. The overall survival rates for factors considered to affect prognosis were calculated using the Kaplan-Meier method. The log-rank test was used to compare survival curves, and P-values of $<0.05$ were considered statistically significant.

\section{RESULTS}

\section{Clinical features of patients}

Mean patient age at time of diagnosis was 50.2 years, 43 patients (4.4\%) were under 35 years old (the younger group), and 926 pa-

Table 1. Characteristics of patients with breast cancer according to age

\begin{tabular}{lcccr}
\hline & \multicolumn{4}{c}{ Age (yr) } \\
\cline { 2 - 4 } & $\begin{array}{c}<35 \\
(\mathrm{n}=43)\end{array}$ & $\begin{array}{c}\geq 35 \\
(\mathrm{n}=926)\end{array}$ & $\begin{array}{c}\text { Total } \\
(\mathrm{n}=969)\end{array}$ & \\
\hline Age $(\mathrm{yr})$ & 30.3 & 51.2 & 50.2 & $<0.001$ \\
Familial history of breast cancer (\%) & 0.5 & 1.7 & 1.6 & 0.001 \\
Menopause & 0 & 438 & 438 & $<0.001$ \\
Childbirth & 1.0 & 1.9 & 1.8 & $<0.001$ \\
Tumor size (cm) & 2.7 & 2.6 & 2.6 & 0.667 \\
Metastatic lymph node & 1.9 & 3.1 & 3.0 & 0.259 \\
Operation method & & & & 0.538 \\
$\quad$ BCS & $28(65.1)$ & $644(69.5)$ & $672(69.3)$ & \\
$\quad$ MRM & $15(34.9)$ & $282(30.5)$ & $297(30.7)$ & \\
Stage & & & & 0.374 \\
I & $10(22.7)$ & $306(32.5)$ & $316(32.1)$ & \\
II & $26(59.1)$ & $418(44.4)$ & $444(45.1)$ & \\
III & $7(15.9)$ & $193(20.5)$ & $200(20.3)$ & \\
IV & $1(2.3)$ & $15(1.6)$ & $16(1.6)$ & \\
\hline
\end{tabular}

Values are mean or number (\%).

$\mathrm{BCS}$, breast-conserving surgery; MRM, modified radical mastectomy.

Stage IV (16 patients) was excluded from this study. tients (95.6\%) were 35 years old or older (the older group). Fifty-nine patients (6.1\% of all study subjects) had breast cancer in their immediate family. Four hundred and thirty-eight postmenopausal women were included in the study, and all were over 35 years old. Mean parity was 1.0 for younger patients and 1.9 for older patients; mean tumor sizes were $2.7 \mathrm{~cm}$ and $2.6 \mathrm{~cm}$, respectively $(\mathrm{P}=0.667)$; and mean numbers of metastatic lymph nodes were 1.9 and 3.1, respectively $(\mathrm{P}=0.259)$. Six hundred and seventy-two patients (69.3\%) underwent breast-conserving surgery, and 297 (30.7\%) underwent mastectomy. Surgical procedures were similar in the two study groups $(\mathrm{P}=0.538)$.

Three hundred and sixteen patients (32.1\%) were of stage I, 444 (45.1\%) were of stage II, 200 (20.3\%) were of stage III, and 16 (1.6\%) were of stage IV. Stage IV (16 patients) was excluded from this study. Stage distributions were similar in the two groups (Table 1).

Six hundred fifty-seven patients $(67.8 \%)$ were positive for hormone receptors, and 312 (32.2\%) were negative for estrogen and progesterone receptors. When estrogen and progesterone receptor expressions were analyzed separately, no significant intergroup difference was observed ( $\mathrm{P}=0.141$ vs. $\mathrm{P}=0.145)$.

HER2/neu was over-expressed in 255 patients (26.3\%) and 424 (43.8\%) were negative for HER2/neu overexpression. Two hundred and ninety (29.9\%) were double positive by IHC, but additional FISH or SISH tests were not performed in these patients.

Among the 124 triple negative patients (12.8\%), patients $<35$ years old had a 2.5 -fold higher rate of triple negativity than patients

Table 2. Hormone receptor and HER2/neu status in patients with breast cancer according to age

\begin{tabular}{lrccc}
\hline & \multicolumn{3}{c}{ Age (yr) } & \\
\cline { 2 - 4 } & $\begin{array}{c}<35 \\
(\mathrm{n}=43)\end{array}$ & $\begin{array}{c}\geq 35 \\
(\mathrm{n}=926)\end{array}$ & $\begin{array}{c}\text { Total } \\
(\mathrm{n}=969)\end{array}$ & \\
\hline HR & & & & 0.096 \\
$\quad$ Positive & $24(55.8)$ & $633(68.4)$ & $657(67.8)$ & \\
$\quad$ Negative & $19(44.2)$ & $293(31.6)$ & $312(32.2)$ & \\
ER & & & & 0.141 \\
$\quad$ Positive & $23(53.5)$ & $605(65.3)$ & $628(64.8)$ & \\
$\quad$ Negative & $20(46.5)$ & $321(34.7)$ & $341(35.2)$ & \\
PR & & & & 0.145 \\
$\quad$ Positive & $19(44.2)$ & $546(59.0)$ & $565(58.3)$ & \\
$\quad$ Negative & $24(55.8)$ & $378(40.8)$ & $402(41.5)$ & \\
HER2/neu & & & & 0.333 \\
$\quad$ Positive & $11(25.6)$ & $244(26.3)$ & $255(26.3)$ & \\
Intermediate & $9(20.9)$ & $281(30.3)$ & $290(29.9)$ & \\
$\quad$ Negative & $23(53.5)$ & $401(43.3)$ & $424(43.8)$ & \\
Triple negative & $13(30.2)$ & $111(12.0)$ & $124(12.8)$ & 0.002 \\
\hline
\end{tabular}

Values are presented as number (\%).

HER2, human epidermal growth factor receptor 2; HR, hormone receptor; ER, estrogen receptor; PR, progesterone receptor. 
$\geq 35$ years old $(30.2 \%$ vs. $12.0 \%, \mathrm{P}=0.002)($ Table 2$)$.

\section{Adjuvant treatment methods and overall survival}

Seven hundred and sixty-five patients (78.9\%) received adjuvant chemotherapy, and of these 39 were $<35$ years old. Treatment results according to hormone receptor status and axillary lymph node metastasis are summarized in Table 3. All 20 patients aged $<35$ years negative for hormone receptors underwent chemotherapy regardless of axillary lymph node metastasis.

Chemotherapy had no significant effect on survival time in patients older than 35 without axillary lymph node metastasis, but in patients with axillary lymph node metastasis, survival time was greater for patients that received chemotherapy (42.1 months vs. 10.8 months, $\mathrm{P}<0.001$ ).

Survival time was longer when chemotherapy plus hormone therapy was used in hormone receptor positive and axillary lymph node metastasis negative patients aged $\geq 35$ (48.7 months vs. 44.4 months, $\mathrm{P}=0.029$ ), but this was not observed in patients $<35$ years.

Radiotherapy was performed in 619 of 671 patients (92.3\%) that received breast-conserving surgery and in 126 of 293 patients (43.0\%) that underwent mastectomy. Radiotherapy achieved a significant increase in survival in patients $<35$ years and $\geq 35$ years that received breast-conserving surgery (45.6 months vs. 19.1 months, $\mathrm{P}=0.047 ; 45.7$ months vs. 31.7 months, $\mathrm{P}<0.001)$ (Table 4).

\section{Prognostic factors and survival rates}

Univariate analysis showed that pregnancy was significantly associated with survival (overall survival/disease-free survival) in patients $<35$ years old (Figs. 1 and 2). In patients $\geq 35$ years, lymph node stage, the presence of progesterone receptor, and triple negative status were significantly associated with survival rate.

Multivariate analysis failed to identify any significant prognostic

Table 3. Distribution of adjuvant systemic chemotherapy according to lymph node and hormone receptor status and outcome according to adjuvant therapy

\begin{tabular}{|c|c|c|c|c|c|c|}
\hline & \multicolumn{3}{|c|}{ Age $<35$ yr $(n=43)$} & \multicolumn{3}{|c|}{ Age $\geq 35$ yr $(n=926)$} \\
\hline & No. of patients & Survival time (mo) & P-value & No. of patients & Survival time (mo) & P-value \\
\hline \multicolumn{7}{|c|}{ Hormone receptor (-) } \\
\hline $\operatorname{LN}(-)$ & & & - & & & 0.540 \\
\hline $\mathrm{CTx}(+)$ & $14(32.6)$ & 36.4 & & $161(17.4)$ & 42.5 & \\
\hline CTx (-) & 0 & - & & $13(14.0)$ & 39.4 & \\
\hline LN (+) & & & - & & & $<0.001$ \\
\hline CTx $(+)$ & $5(11.6)$ & 35.9 & & $113(12.2)$ & 42.1 & \\
\hline CTx (-) & 0 & - & & $5(0.5)$ & 10.8 & \\
\hline \multicolumn{7}{|c|}{ Hormone receptor (+) } \\
\hline LN (-) & & & 0.597 & & & 0.029 \\
\hline CTx $(+)$ & $8(18.6)$ & 43.5 & & $201(21.7)$ & 48.7 & \\
\hline CTx $(-)$ & $5(11.6)$ & 48.8 & & 159 (17.2) & 44.4 & \\
\hline $\operatorname{LN}(+)$ & & & - & & & 0.199 \\
\hline CTx $(+)$ & $11(25.6)$ & 56.5 & & $252(27.2)$ & 45.1 & \\
\hline CTx $(-)$ & 0 & - & & $17(1.8)$ & 35.0 & \\
\hline
\end{tabular}

Values are presented as number (\%) or median.

LN, lymph node; CTx, chemotherapy.

Table 4. Distribution of adjuvant radiation therapy according to operation method and outcome

\begin{tabular}{|c|c|c|c|c|c|c|}
\hline & \multicolumn{3}{|c|}{ Age $<35$ yr $(n=43)$} & \multicolumn{3}{|c|}{ Age $\geq 35$ yr $(n=926)$} \\
\hline & No. of patients & Survival time (mo) & P-value & No. of patients & Survival time (mo) & P-value \\
\hline BCS & & & 0.047 & & & 0.001 \\
\hline $\mathrm{RTx}(+)$ & $25(58.1)$ & 45.6 & & $594(64.1)$ & 45.7 & \\
\hline RTx (-) & $3(7.0)$ & 19.1 & & $49(5.3)$ & 31.7 & \\
\hline MRM & & & 0.634 & & & 0.567 \\
\hline $\mathrm{RTx}(+)$ & $8(18.6)$ & 49.5 & & $118(12.7)$ & 44.8 & \\
\hline $\mathrm{RTx}(-)$ & $7(16.3)$ & 44.2 & & $160(17.3)$ & 43.4 & \\
\hline
\end{tabular}

Values are presented as number (\%) or median.

$\mathrm{BCS}$, breast-conserving surgery; RTx, radiation therapy; MRM, modified radical mastectomy. 

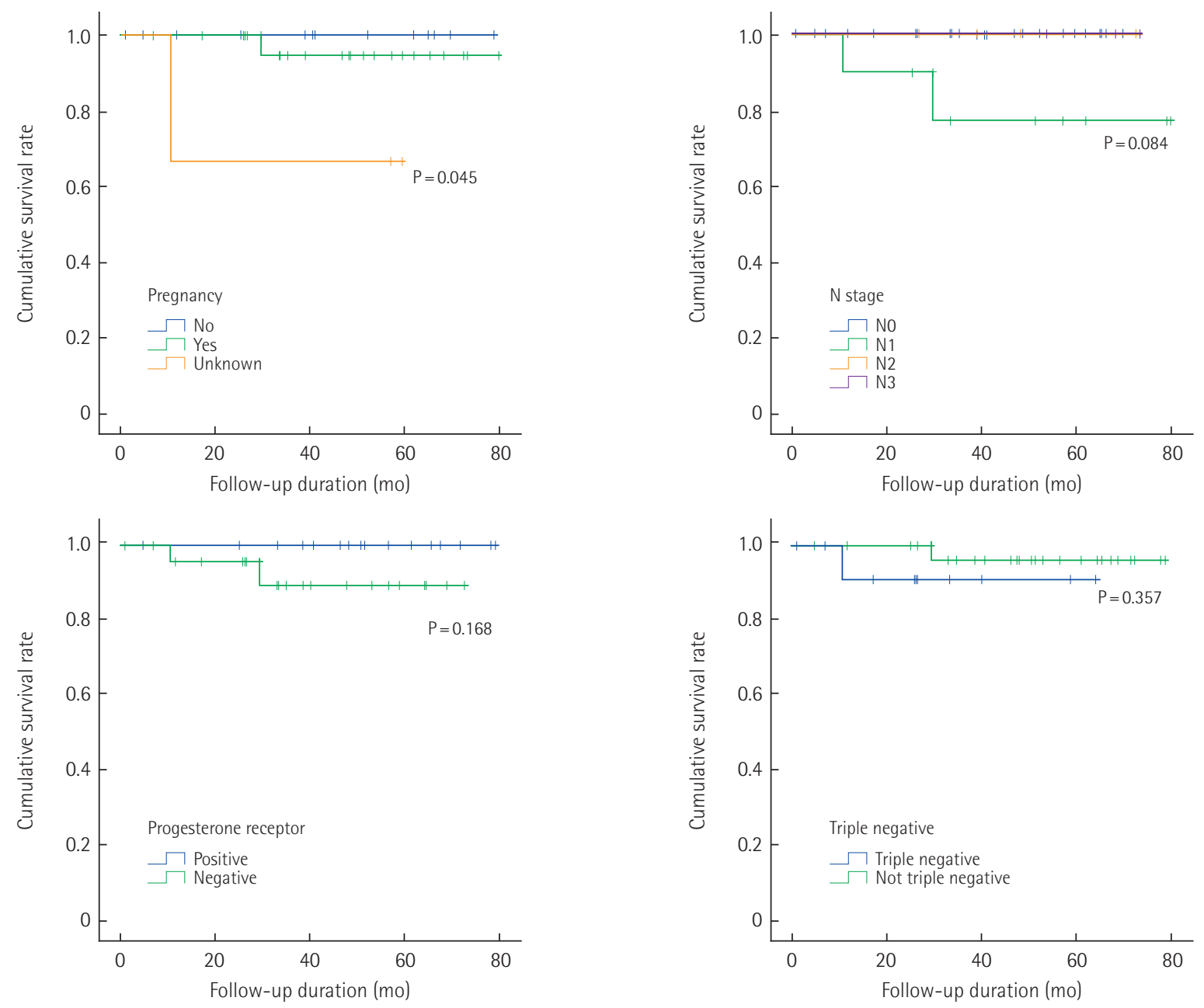

Fig. 1. Overall survival according to prognostic factors $(<35 \mathrm{yr})$.

Table 5. Multivariate analysis on factors affecting overall survival

\begin{tabular}{llll}
\hline Factor & HR & \multicolumn{1}{c}{$95 \% \mathrm{Cl}$} & P-value \\
\hline Age $<35$ yr $(n=43)$ & & & \\
Triple negative & 4.141 & $0.000-2.076 \mathrm{E}+150$ & 0.994 \\
LN & 0.593 & $0.200-1.756$ & 0.345 \\
RTx & 0.070 & $0.001-6.645$ & 0.252 \\
Pregnancy & 0.824 & $0.000-6.959 \mathrm{E}+45$ & 0.972 \\
Age $\geq 35$ yr $(n=926)$ & & & \\
Familial history & 8.894 & $1.685-46.962$ & 0.010 \\
Triple negative & 8.800 & $2.276-34.022$ & 0.002 \\
Childbirth & 1.950 & $1.240-3.064$ & 0.004 \\
\hline
\end{tabular}

$H R$, hazard ratio; $\mathrm{Cl}$, confidence interval; $L N$, lymph node; $R T x$, radiation therapy.

factor of survival rate in patients $<35$ years, but showed triple negativity, familiar history, and childbirth were significantly associated with poorer survival in patients older 35 (Table 5).

\section{DISCUSSION}

The incidence of breast cancer is a rapidly increasing worldwide. It has a higher incidence that any other cancer in women globally, and is the second most common cancer in Korean women after thyroid cancer (15.4\% in 2013). In Korea, survival is also increasing due to aggressive breast cancer screening and improved standardized treatments [2].

The causes of breast cancer have not yet to be clearly identified, known risk factors include estrogen exposure duration (early menarche, late menopause and older childbirth, breast feeding), obesity, alcohol consumption, hormone replacement therapy, oral contraceptive use, and a positive family history [5].

The incidence of breast cancer is known to be age dependent. In Korea, its incidence peaks in the 40s and is higher in premenopausal women than in the West. Furthermore, its incidence among younger women ( $<40$ years) currently stands at $\sim 11.0 \%$, which is more than twice that found in the West [6]. Breast cancer is gener- 

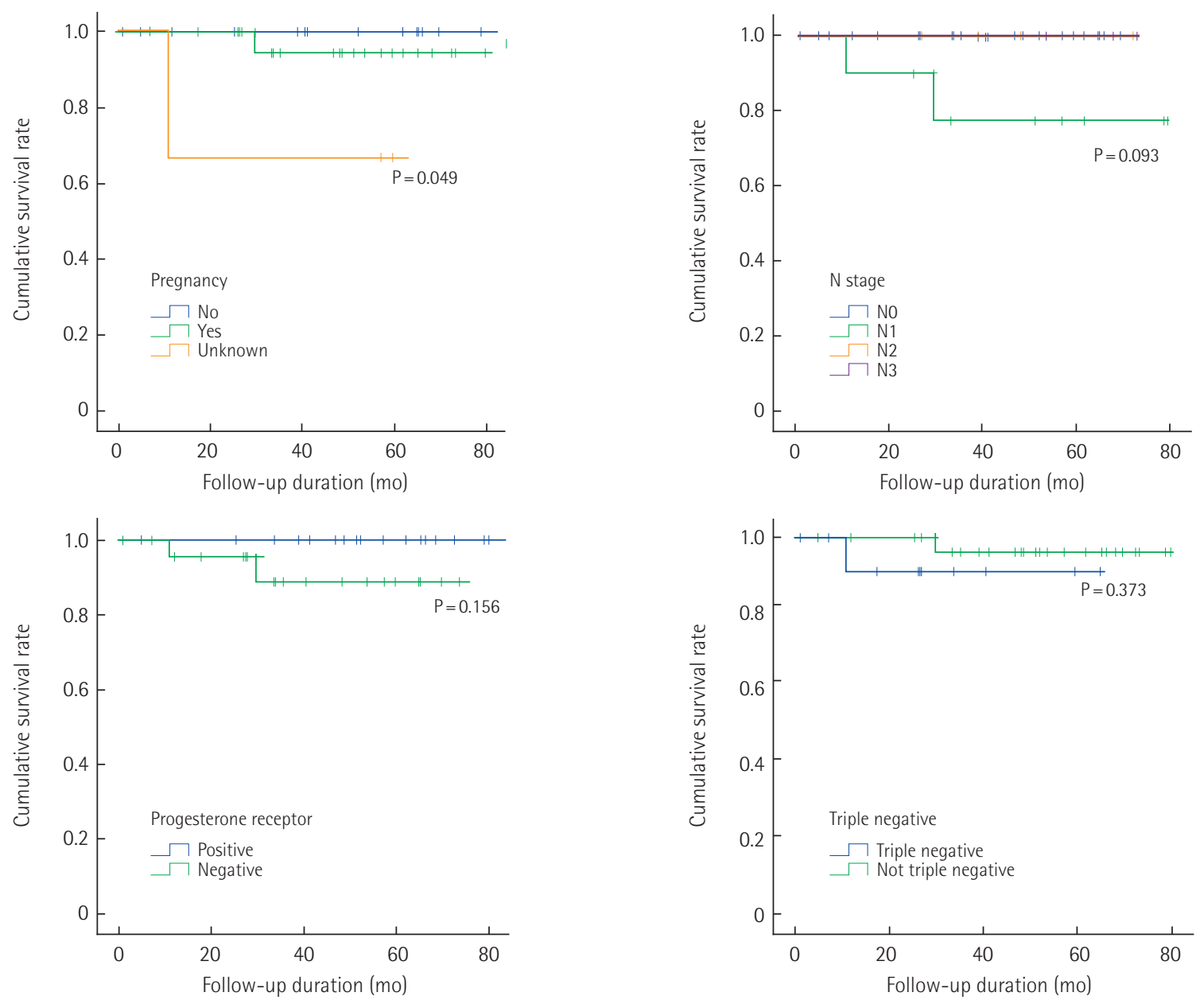

Fig. 2. Disease-free survival according to prognostic factors ( $<35 \mathrm{yr})$.

ally considered more aggressive in younger women, though studies differ. However, it is important that other factors than might influence survival be considered $[7,8]$. Because clinical characteristics and prognoses may be age-dependent, considerations of age may be important during treatment planning. In particular, young women in their 20s and 30s experience rapid physiological changes due to pregnancy, childbirth, breastfeeding, and intense social activity. Therefore, it is important that concerted efforts be made to improve survival rates by identifying clinical characteristics and prognostic factors of breast cancer in young patients.

In a study conducted by the Korean Breast Cancer Society, the proportion of breast cancer patients aged $<35$ years ranged from $11.3 \%$ to $17.3 \%$ [9]. In the present study, 43 of 969 breast cancer patients (4.4\%) fell into this age category. Furthermore, we found younger and older patients did not differ significantly with respect to tumor size or metastatic lymph node numbers. Although the proportion of postmenopausal women and parity were substantially lower in younger patients.
Twenty-eight of 43 (65.1\%) under age 35 and 644 of 926 (69.5\%) over 35 years underwent breast-conserving surgery. Both groups showed higher rates of breast-conserving surgery than mastectomy. Surgical procedures were not found to affect prognosis, indicating breast-conserving surgery should continue to be favored because its effect on body image is less than that of mastectomy.

In patients $<35$ and $\geq 35$ years, the most common stage was stage 2 and incidences rates were similar, and stage and age were not found to be related. Education on the importance of continuous self-examination and mammography, should be conducted to increase the rate of early breast cancer detection.

Analysis of hormone receptor (estrogen and progesterone, HER2/neu) results revealed no significant difference between our two study groups, but the proportion of triple-negative cases was 2.5 times higher in the younger group. We suggest more studies should be performed to determine whether a triple negative status is related to poor prognosis in young breast cancer patients [10].

Older patients positive for hormone receptors but without 
lymph node metastasis had a better prognosis when they received adjuvant chemotherapy and survival was increased by chemotherapy in older patients negative for hormone receptors with lymph node metastasis.

It was not possible to analyze survival rates with respect to chemotherapy in the younger age group because all 19 hormone receptor negative patients received chemotherapy. However, in younger patients that were hormone receptor positive without lymph node metastasis, chemotherapy did not significantly affect survival.

When radiation therapy was performed after breast-conserving surgery, the survival rate tended to increase in the younger group (45.6 months vs. 19.1 months, $\mathrm{P}=0.047$ ), but increased significantly in the older group (45.7 months vs. 31.7 months, $\mathrm{P}<0.001$ ) On the other hand, radiotherapy did not have a significant effect in younger or older patient that underwent mastectomy, which supports the standard use of breast conservation surgery plus postoperative radiation therapy [3].

Univariate analysis showed that pregnancy affected survival in the younger group, but that lymph node metastasis, hormone (progesterone, estrogen) receptor status, and triple negativity affected survival in the older group.

This study confirms that in breast cancer patients, prognostic factors are age-dependent. In particular, in the younger group survival rate was lower in those with a history of pregnancy, and in the older group survival rate was lower for a lymph node stage, when hormone receptor was negative, and for a triple negative status.

In one study, patients without lymph node metastasis were found to enjoy the almost the same lifespan as the general population regardless of age [11]. Gajdos et al. [12] reported younger patients exhibited lower tumor differentiation and lower positive rates for estrogen and progesterone receptors than older patients. Diab et al. [11] reported a case of an older breast cancer patient with better biologic prognostic features, such as, a high hormone receptor expression, normal p53 expression, and HER2/neu. In the present study, hormone receptor expression frequencies were generally similar in the two study groups, but hormone receptor expression frequency tended to be lower in the younger group (estrogen receptor, $53.5 \%$ vs. $65.3 \%$; progesterone receptor, $44.2 \%$ vs. 59.0\%; HER2/neu, $25.6 \%$ vs. $26.3 \%$ ). Furthermore, triple negative breast cancer was significantly more frequent in the younger group.

A previous study, EBCTCG meta-analysis showed that the combination of chemotherapy and hormone therapy was effective in breast cancer patients positive for hormone receptors, but no significant survival improvement was observed in younger $(<40$ years old) patients [13].
Satariano [14] reported that breast cancer patients with two or more comorbid conditions, such as, heart disease or diabetes, had a 2.2-fold higher risk of mortality than patients without a comorbidity, and suggested studies be undertaken to determine the natures of interactions between liver disease, pulmonary disease, and other malignant tumors on the treatment of breast cancer.

Summarizing, pregnancy were found to be important prognostic factors in breast cancer patients younger than 35 years old. In addition, lymph node metastasis and triple negativity were found to have non-significant negative effects on prognosis in this group. However, the proportion of patients under 35 years of age was low in the present study (4.4\%, 43/69 patients). Thus, we recommend additional studies be performed to confirm our findings in a larger cohort.

\section{CONFLICT OF INTEREST}

No potential conflict of interest relevant to this article was reported.

\section{REFERENCES}

1. Siegel R, Ma J, Zou Z, Jemal A. Cancer statistics, 2014. CA Cancer J Clin 2014;64:9-29.

2. Jung KW, Won YJ, Oh CM, Kong HJ, Lee DH, Lee KH, et al. Cancer statistics in Korea: incidence, mortality, survival, and prevalence in 2014. Cancer Res Treat 2017;49:292-305.

3. Ministry of Health and Welfare. Cancer statistics [Internet]. Goyang (Korea): National Cancer Information Center [cited 2017 Aug 14]. Available from: http://www.cancer.go.kr.

4. Min YK, Kim JH, Cho SJ, Kim NR, Koo BH, Whang CW, et al. Clinical characteristics and prognosis of young age (35 year old or younger) onset breast cancer. J Korean Surg Soc 2001;60:612-17.

5. Paik NS. Current status of breast cancer in Korea. Ewha Med J 2014;37:69-74.

6. National Cancer Center. Annual report of cancer statistics in Korea in 2014. Sejong: Ministry of Health and Welfare; 2016.

7. Lee SD, Park HL, Nam SJ, Yang JH, Ko YH. Breast cancer in third decade: does it really have a poor prognosis? J Korean Breast Cancer Soc 2001;4:63-7.

8. Crowe JP Jr, Gordon NH, Shenk RR, Zollinger RM Jr, Brumberg DJ, Shuck JM. Age does not predict breast cancer outcome. Arch Surg 1994;129:483-7.

9. Korean Breast Cancer Society. The breast. 2nd ed. Seoul: Ilchokak; 2005.

10. Foulkes WD, Smith IE, Reis-Filho JS. Triple-negative breast cancer. N Engl J Med 2010;363:1938-48.

11. Diab SG, Elledge RM, Clark GM. Tumor characteristics and clini- 
cal outcome of elderly women with breast cancer. J Natl Cancer Inst 2000;92:550-6.

12. Gajdos C, Tartter PI, Bleiweiss IJ, Lopchinsky RA, Bernstein JL. The consequence of undertreating breast cancer in the elderly. J Am Coll Surg 2001;192:698-707.
13. Early Breast Cancer Trialists' Collaborative Group. Polychemotherapy for early breast cancer: an overview of the randomized trials. Lancet 1998;352:930-42.

14. Satariano WA. Aging, comorbidity, and breast cancer survival: an epidemiologic view. Adv Exp Med Biol 1993;330:1-11. 